\title{
TGF $\alpha$-PE38 enhances cytotoxic T-lymphocyte killing of breast cancer cells
}

\author{
STEPHEN E. WRIGHT ${ }^{1-4}$, KATHLEEN A. REWERS-FELKINS ${ }^{1}$, IMELDA QUINLIN ${ }^{1}$, NAZRUL I. CHOWDHURY ${ }^{1}$, \\ JEWEL AHMED $^{1}$, PAUL W. ELDRIDGE ${ }^{4}$, SANJAY K. SRIVASTAVA ${ }^{3}$ and IRA PASTAN ${ }^{5}$ \\ ${ }^{1}$ Women's Health Research Institute, Department of Internal Medicine; ${ }^{2}$ Department of Microbiology and Immunology, \\ School of Medicine; ${ }^{3}$ Department of Biomedical Sciences, School of Pharmacy, Texas Tech University Health Sciences Center; \\ ${ }^{4}$ Harrington Cancer Center, Amarillo, TX 79106; ${ }^{5}$ Laboratory of Molecular Biology, Center for Cancer Research, \\ National Cancer Institute, National Institutes of Health, Bethesda, MD 20892-4264, USA
}

Received October 2, 2013; Accepted December 13, 2013

DOI: $10.3892 / \mathrm{ol} .2014 .1969$

\begin{abstract}
The aim of the present study was to determine whether the combination of two modalities of immunotherapy, targeting two different tumor antigens, may be feasible and non-toxic, yet enhance the killing of a human breast cancer cell line. The first modality was tumor growth factor $\alpha$-Pseudomonas exotoxin 38 (TGF $\alpha$-PE38), which specifically targets and kills tumor cells that express the epidermal growth factor receptor. The second modality was mucin-1 (MUC1)-specific cytotoxic T lymphocytes (CTLs), generated by MUC1 stimulation of peripheral blood mononuclear cells, to target the human breast cancer cell line, MCF7. TGF $\alpha$-PE38 exhibited specific lysis of the MCF7 cells in a concentration- and time-dependent manner. TGF $\alpha$-PE38 did not kill the normal hematopoietic stem cells or CTLs. Furthermore, TGF $\alpha$-PE38 was not inhibitory for the growth or differentiation of the normal human hematopoietic stem cells into erythroid and myeloid colonies. In addition, TGF $\alpha$-PE38 did not inhibit the killing function of CTLs, either when preincubated or co-incubated with CTLs. Finally, therapeutic enhancement was observed, in that TGF $\alpha$-PE38 and CTLs were additive in the specific lysis of the MCF7 cells. These two modalities of immunotherapy may be beneficial for humans with breast cancer with or without other therapies, including autologous hematopoietic stem cell transplantation, specifically for purging cancer cells from hematopoietic stem cells prior to transplantation.
\end{abstract}

Correspondence to: Dr Stephen E. Wright, Women's Health Research Institute, Department of Internal Medicine, Texas Tech University Health Sciences Center, 1400 Wallace Blvd., Amarillo, TX 79106, USA

E-mail: stephen.wright@ttuhsc.edu

Key words: TGF $\alpha-\mathrm{PE} 38$, cytotoxic T lymphocyte, cancer, breast, mucin-1

\section{Introduction}

Therapeutic agents that target tumor specific antigens have the potential to produce effective treatment while minimizing side-effects. Combining therapeutic agents that target more than one tumor antigen may enhance the killing of tumor cells. In addition, a combination of therapeutic agents, targeting multiple antigens, may prevent the escape of tumor cells if one of the antigens is no longer presented. One such tumor antigen that is overexpressed on tumor cells is the epidermal growth factor receptor (EGFR) (1). Targeting may be via the ligand for EGFR, EGF. Fusion of a toxin to a ligand for the receptor produces a specifically targeted cytotoxic agent (1). Receptor-mediated endocytosis internalizes the toxin, which causes cell death (2). One such toxin is Pseudomonas exotoxin (PE) (1). Tumor growth factor $\alpha(\mathrm{TGF} \alpha)$ is similar in structure to EGF and binds to EGFR at a similar rate (3). Since conjugation of PE to EGF is inefficient, TGF $\alpha$ is often selected as an alternative (1). TGF $\alpha$-PE38 is cytotoxic to tumor cells in vitro (4). Furthermore, a preclinical study in athymic, nude mice demonstrated the effectiveness of TGF $\alpha-P E 38$ in reducing the size of human brain tumor cell lines (5). Based on these studies, TGF $\alpha$-PE38 was selected as one of the targeted therapies.

The second targeted therapy was that of mucin-1 (MUC1)-stimulated peripheral blood mononuclear cells (PBMCs; M1SMC), which produce cytotoxic T lymphocytes (CTLs) that kill human breast cancer cells in vitro (6) and prevent human breast cancer cell tumor development in vivo in non-obese diabetic, severe combined immunodeficient (NOD-SCID) mice (7).

\section{Materials and methods}

Human cells. All human cells were obtained from deceased subjects in accordance with the Texas Tech University Health Sciences Center institutional review board. The study was approved by the ethics committee of Texas Tech University Health Sciences Centre (Amarillo, TX, USA). Frozen human peripheral blood hematopoietic stem cells (HSCs) were obtained from the Bone Marrow Transplant Laboratory of 
the Harrington Cancer Center (Amarillo, TX, USA) from deceased, anonymous donors. Frozen PBMCs were acquired by apheresis from a deceased, anonymous donor with breast adenocarcinoma.

TGF $\alpha$-PE38, a gift from Ira Pastan, National Cancer Institute (Bethesda Maryland, USA), was aliquoted and stored at $-70^{\circ} \mathrm{C}$.

MUC1 peptides. A single repeat of the MUC1-variable number tandem repeat (VNTR)1 peptide, GSTAPPAHGVTSAPD TRPAP (8), was synthesized by American Peptide Co., Inc. (Sunnyvale, CA, USA).

Cell culture conditions. Procedures were performed as described previously (6). The PBMCs were not HLA typed, since our previous studies $(7,9,10)$ and other studies (11) have found that cytotoxicity by M1SMC may be non-major histocompatibility complex (MHC)-restricted. Cells were cultured at $2 \times 10^{6}$ cells $/ \mathrm{ml}$ in AIM-V ${ }^{\circledR}$ serum-free lymphocyte medium (GIBCO-BRL, Life Technologies Inc., Grand Island, NY, USA) and maintained in a $37^{\circ} \mathrm{C}$ humidified $5 \% \mathrm{CO}_{2}$ atmosphere (12). Interleukin (IL)-2 (Cetus Corporation, Berkeley, CA, USA) was added twice per week at $100 \mathrm{IU} / \mathrm{ml}$. The cells were stimulated with MUC1-VNTR1 peptide on days zero and seven, at $1 \mu \mathrm{g} / \mathrm{ml}$. The cells were harvested on day eight. HSCs were cultured at $2 \times 10^{6}$ cells $/ \mathrm{ml}$ in AIM-V ${ }^{\circledR}$.

Cytotoxicity assays. The MCF7 (HLA-A2) breast cancer cell line was obtained from the American Type Culture Collection (ATCC, Manassas, VA, USA) and cultured as recommended. MCF7 cells express hypoglycosylated mucin (13). This cell line was used as the target cell line in an XTT ${ }^{\circledR}$ assay (Roche Diagnostics Corp., Indianapolis, IN, USA) $(14,15)$ performed according to the manufacturer's instructions. The TGFo-PE38 or effector cells were tested at a concentration of effector-to-target cell ratio of 1.25. Medium was added in place of effector cells to the spontaneous release control wells. The effector and target cells were incubated together for $18 \mathrm{~h}$, which we had previously found to be superior to $4 \mathrm{~h}(6)$, at $37^{\circ} \mathrm{C}$ and $5 \% \mathrm{CO}_{2}$. This was performed in triplicate. The percentage of specific lysis $(\% \mathrm{SL})=$ [OD(target - medium) - OD(A - B)]/OD(target - medium) x100, where A represents the experimental (target plus effectors) wells and $\mathrm{B}$ represents the wells with a corresponding number of effectors.

Other assays. Other assays included the Trypan Blue Cell Viability Solution assay (Sigma-Aldrich, St. Louis, MO, USA) (16), the DePsiphler Mitochondrial Potential assay (R\&D Systems, Inc., Minneapolis, MN, USA) (17) and the in situ chromium uptake assay (18), performed according to the manufacturer's instructions.

Progenitor assay. The cells to be tested for progenitor cell content were thawed and washed to remove cryoprotectant. The cells were counted and added to cultures at $5 \times 10^{5}$ cells/ $\mathrm{ml}$ in methylcellulose (MethoCult media ${ }^{\mathrm{TM}}$; Stem Cell Technologies, Vancouver, BC, Canada) according to the manufacturer's instructions (19). Cultures were examined after 14 days and scored for the presence of erythroid [burst forming unit-erythroid (BFU-E)] and myeloid

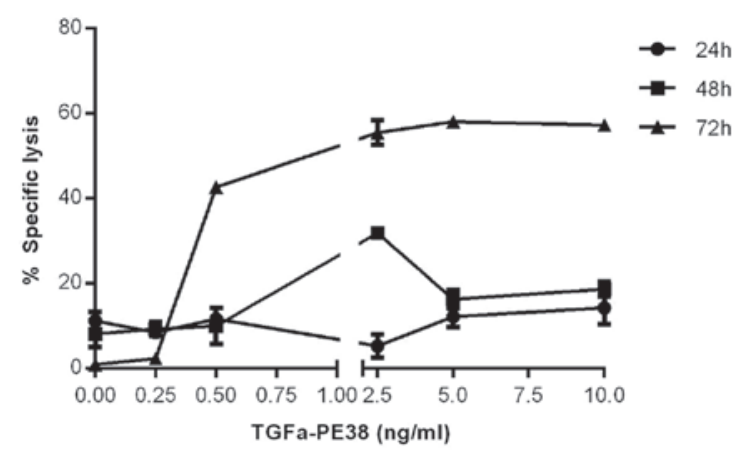

Figure 1. Concentration-dependent specific lysis of MCF7 cells by TGF $\alpha$-PE38. MCF7 cells were incubated with increasing concentrations of TGF $\alpha$-PE38 for 24,48 or $72 \mathrm{~h}$. The percentage of specific lysis (\%SL) was determined by the XTT assay. This data is representative of two experiments using the XTT assay. Bars are standard error of the mean $(\mathrm{N}=3)$. Error bars are hidden in some of the data points. Other assays, including the Trypan Blue Cell Viability Solution assay, the DePsiphler mitochondrial potential assay and the in situ chromium uptake assay, produced similar results, but with a wider range of error. TGF, tumor growth factor; PE, Pseudomonas endotoxin.

(colony-forming unit-granulocytes, monocytes (CFU-GM)] progenitor colonies.

Statistical analysis. Fisher's exact test, the $\chi^{2}$ test, the Kruskal-Wallis test and the Mann-Whitney signed rank test were used to analyze data. $\mathrm{P}<0.05$ was considered to indicate a statistically significant difference.

\section{Results}

Concentration- and time-dependent specific lysis of $M C F 7$ cells by TGF $\alpha-P E 38$. Based upon the reported $\mathrm{IC}_{50}$ (concentration of immunotoxin causing a 50\% reduction in protein synthesis) for MCF7 cells of $1.1 \mathrm{ng} / \mathrm{ml}$ when using TGF $\alpha$-PE38 (4), an analysis of the \%SL of the MCF7 cells at a range of TGF $\alpha-P E 38$ concentrations below and above this value were performed to determine the optimum concentration for use in combination with CTLs. The 50\% lysis of the MCF7 cells by TGF $\alpha-P E 38$, which was between 0.5 and $2.5 \mathrm{ng} / \mathrm{ml}$ at $72 \mathrm{~h}$ of incubation (Fig. 1), agreed with the reported $\mathrm{IC}_{50}$ data (4). Other assays, including the Trypan Blue Cell Viability Solution assay (16), the DePsiphler Mitochondrial Potential assay (17) and the in situ chromium uptake assay (18), produced similar results, but with a wider range of error. The \%SL plateaued at $5 \mathrm{ng} / \mathrm{ml} \mathrm{TGF} \alpha-\mathrm{PE} 38$ (Fig. 1) and thus was used for the study of time-dependent specific lysis of the MCF7 cells by TGF $\alpha$-PE38. There was little (3\%) specific lysis of the MCF7 cells by TGF $\alpha$-PE38 at $24 \mathrm{~h}$, however, this increased exponentially to 50 and $81 \%$ at 48 and $72 \mathrm{~h}$, respectively (Fig. 2).

Effect of TGF $\alpha$-PE38 on HSC viability. To determine if TGF $\alpha$-PE38 was non-toxic in normal cells, frozen human peripheral blood HSCs were thawed and incubated with or without $5 \mathrm{ng} / \mathrm{ml} \mathrm{TGF \alpha -PE38} \mathrm{for} \mathrm{five} \mathrm{days.} \mathrm{The} \mathrm{five-day}$ incubation time was selected, as we had shown that the majority of MCF7 cells were killed by TGF $\alpha-P E 38$ at $72 \mathrm{~h}$. The percentage of remaining live HSCs was similar with or without TGF $\alpha$-PE38 (106 and 100\%, respectively; Fig. 3). 


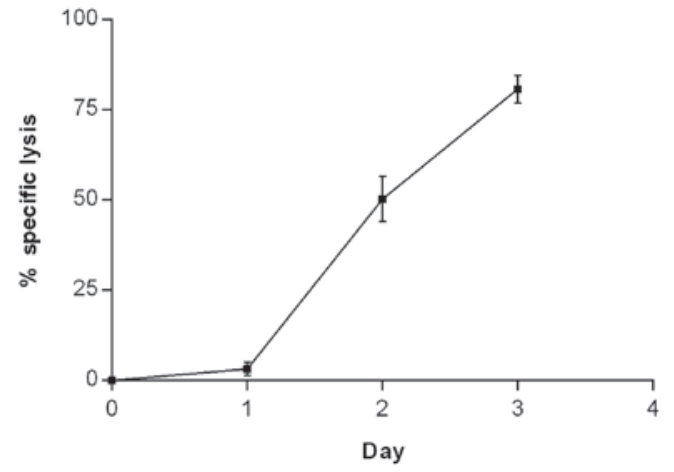

Figure 2. Time-dependent specific lysis of MCF7 cells by TGF $\alpha$-PE38. MCF7 cells were incubated with $5 \mathrm{ng} / \mathrm{ml} \mathrm{TGF \alpha -PE38}$ for 1,2 or 3 days. The percentage of specific lysis (\%SL) was determined by the XTT assay. This data is representative of two experiments using the XTT assay. Bars are standard error of the mean $(n=3)$. Other assays, including the trypan blue viability assay and the in situ chromium uptake assay, produced similar results, but with a wider range of error. TGF, tumor growth factor; PE, Pseudomonas endotoxin.

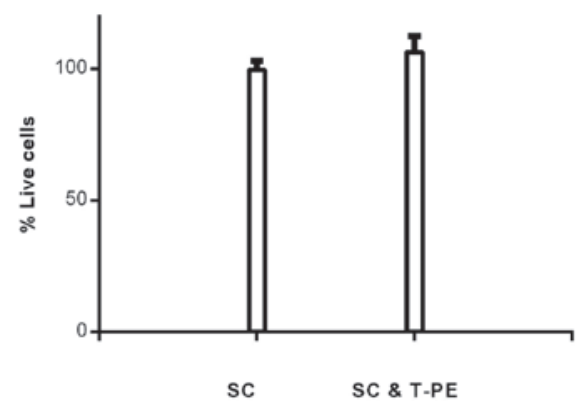

Figure 3. Effect of TGF $\alpha$-PE38 (T-PE) on hematopoietic stem cell (HSC) viability. HSC were incubated with $5 \mathrm{ng} / \mathrm{ml}$ T-PE for five days. $\mathrm{n}=4$ without T-PE and $n=9$ with T-PE. The percentage of remaining live cells was determined by the XTT assay. Bars are standard error of the mean. TGF, tumor growth factor; PE, Pseudomonas endotoxin.

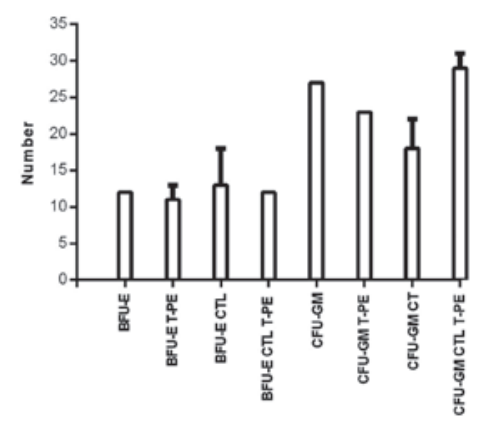

Figure 4. Effect of TGF $\alpha$-PE38 (T-PE) on hematopoietic stem cell (HSC) erythroid [burst forming unit-erythroid (BFU-E)] and myeloid [colony-forming unit-granulocytes, monocytes (CFU-GM)] progenitor colonies. HSCs were incubated with or without $5 \mathrm{ng} / \mathrm{ml} \mathrm{T-PE}$ and/or CTLs at an effector-to-target ratio of 1.25 for 14 days. The number of BFU-E and CFU-GM were determined by a methylcellulose assay. There was no statistical difference in any group of BFU-E or CFU-GM compared with the other BFU-E or CFU-GM groups, respectively (Kruskal-Wallis test). Bars are standard error of the mean $(n=2)$. Error bars are hidden in some of the data points. TGF, tumor growth factor; PE, Pseudomonas endotoxin; CTL, cytotoxic T lymphocytes.

Effect of TGF $\alpha$-PE38 and/or CTLs on HSC growth and differentiation. To determine if TGF $\alpha$-PE3 8 and/or CTLs were inhibitory for growth and differentiation of normal

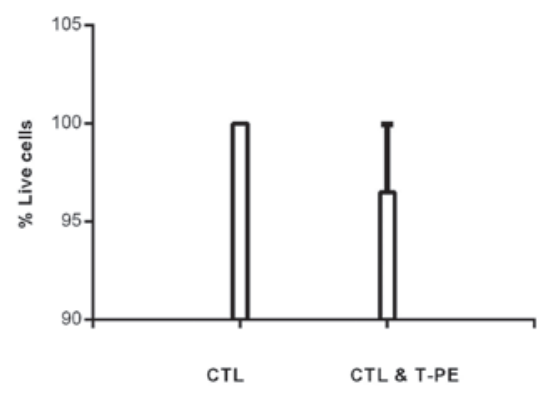

Figure 5. Effect of TGFa-PE38 (T-PE) on CTL cell viability. CTLs were incubated with $5 \mathrm{ng} / \mathrm{ml}$ T-PE for three days. The percentage of remaining live cells was determined by the XTT assay. CTLs incubated without T-PE versus with T-PE, $\mathrm{P}=0.87\left(\chi^{2}\right.$ test). Bars are standard error of the mean $(n=2)$. CTLs alone was set to $100 \%$, so the error bar is not shown. TGF, tumor growth factor; PE, Pseudomonas endotoxin; CTL, cytotoxic T lymphocytes.

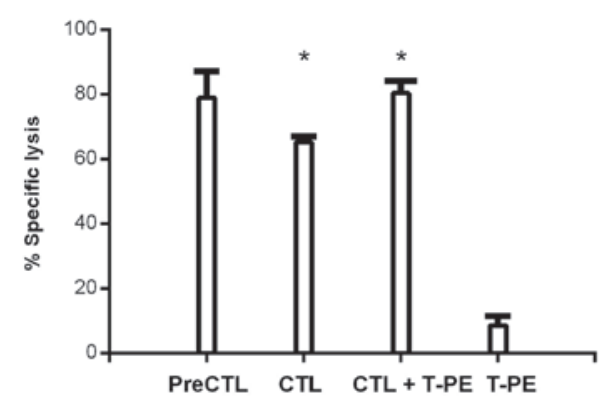

Figure 6. Specific lysis of MCF7 by CTLs, preincubated (PreCTLs) or not (CTL) with TGFo-PE38 (T-PE), and CTLs co-incubated with T-PE (CTL + T-PE) or not. MCF7 cells were incubated with CTLs preincubated with $0.25 \mathrm{ng} / \mathrm{ml} \mathrm{T-PE}$ for one day (PreCTL) or not (CTL) at an effector (CTL)-to-target (MCF7) ratio (E:T) of 1.25 for one day. The third group was CTLs at an E:T of 1.25 co-incubated with or without $0.25 \mathrm{ng} / \mathrm{ml} \mathrm{T-PE} \mathrm{for} \mathrm{one}$ day (CTL + T-PE). The percentage of specific lysis (\%SL) was determined by the XTT assay. Preincubation of CTLs with T-PE (Pre CTL) vs. CTL, $\mathrm{P}=0.48$ (NS; Mann-Whitney Rank Sum test). CTLs co-incubated with T-PE $(\mathrm{CTL}+\mathrm{T}-\mathrm{PE})$ vs. $\mathrm{CTL},{ }^{*} \mathrm{P}=0.01$. Pre $\mathrm{CTL}$ vs. $\mathrm{CTL}+\mathrm{T}-\mathrm{PE}, \mathrm{P}=0.22$ (NS) Results were similar for E:T ratios of 0.625 and 2.5. Bars are standard error of the mean $(\mathrm{n}=3)$. TGF, tumor growth factor; PE, Pseudomonas endotoxin; CTL, cytotoxic T lymphocytes; NS, not significant.

cells, frozen human peripheral blood HSCs were thawed and incubated with or without $5 \mathrm{ng} / \mathrm{ml} \mathrm{TGF} \alpha-P E 38$ and/or CTLs for 14 days. The 14-day incubation time was selected since this is the time required to see macroscopic colonies in order to assay for BFU-E and CFU-GM (19). The mean number of BFU-E and CFU-GM were not significantly different with or without TGF $\alpha$-PE38 (BFU-E with, 11, and without, 12; and CFU-GM with, 23, and without, 27) or for CTLs with or without TGF $\alpha$-PE38 (BFU-E with, 12, and without, 13; and CFU-GM with, 29, and without, 18) (Fig. 4).

Effect of TGF $\alpha$-PE38 on CTL cell viability. To determine if TGF $\alpha$-PE38 was non-toxic for CTLs, CTLs were incubated with or without $5 \mathrm{ng} / \mathrm{ml}$ TGF $\alpha-P E 38$ for three days. The three-day incubation time was selected, as we had shown that the majority of the MCF7 cells were killed by TGF $\alpha$-PE38 at $72 \mathrm{~h}$ and that the lytic function of CTLs was reduced with time in culture (6). The percentage of remaining live CTLs was similar with or without TGF $\alpha$-PE38 (97 and 100\%, respectively; Fig. 5). 
Effect of TGF $\alpha-P E 38$ on the killing function of CTLs. To determine if TGF $\alpha$-PE38 inhibited the killing function of CTLs, CTLs were incubated with or without TGF $\alpha$-PE38 for one day. The one-day preincubation time was selected, as the lytic function of CTLs is reduced with time in culture (6). The \%SL of the MCF7 cells by CTLs was not inferior following preincubation with TGFo-PE38 (79\%) versus without TGF $\alpha$-PE38 (65\%) (Fig. 6). To determine if TGF $\alpha$-PE38 enhanced the specific lysis of the MCF7 cells by CTLs, TGF - PE38 was co-incubated with CTLs in a one-day specific lysis assay of the MCF7 cells. The one-day incubation time was selected, as this is the standard time for the MCF7 specific lysis assay (6). The concentration of TGF $\alpha$-PE38 was lowered to obtain a specific lysis of the MCF7 cells of 9\%, so that an additive effect of CTLs could be observed. Co-incubation with CTLs and TGF $\alpha$-PE38 produced additive effects in the specific lysis of the MCF7 cells (80\%) (Fig. 6). This result was significantly different $(\mathrm{P}=0.01)$ to $\mathrm{CTLs}$ alone $(65 \%)$. The specific lysis of the MCF7 cells following co-incubation with CTLs and TGF $\alpha$-PE38 (80\%) was not significantly different $(\mathrm{P}=0.22)$ to CTLs preincubated with TGF $\alpha$-PE38 (79\%) (Fig. 6).

\section{Discussion}

We aimed to affirm or refute whether the combination of two modalities of immunotherapy, targeting two different tumor antigens, may be feasible and non-toxic, yet enhance killing of a human breast cancer cell line. The first target selected was EGFR, since it is present on multiple types of tumors (1). Since TGF $\alpha$ is similar in structure to EGF and binds to EGFR at a similar rate as EGF (3), it was selected as the ligand for EGFR. Additionally, since fusion of a toxin to a ligand for the receptor produces a specifically targeted cytotoxic agent (1), a ligand, TGF $\alpha$, fused to a toxin, PE, was used (1). TGF $\alpha$-PE38 has been shown to be cytotoxic to tumor cells in vitro (4). In addition, TGF $\alpha-P E 38$ reduces the size of human brain tumor cell lines in athymic, nude mice (5). As predicted from these previous studies, TGF $\alpha$-PE38 was shown to lyse a human breast cancer cell line, MCF7, in a concentration- and time-dependent manner. In order for a product to be used in humans it must be non-toxic for normal cells. Therefore, TGF $\alpha$-PE38 was evaluated for toxicity against normal cells. It was non-toxic for normal cells, specifically for frozen human peripheral blood HSCs. Furthermore, TGF $\alpha$-PE38 did not inhibit the function of peripheral blood HSCs. The second targeted therapy was M1SMC, which produce CTLs. We previously demonstrated that these kill human breast cancer cells in vitro (6), and prevent human breast cancer cell tumor development in vivo in NOD-SCID mice (7). TGF $\alpha$-PE38 was not only non-toxic to CTLs, but it also did not inhibit the specific lysis of a human breast cancer cell line by CTLs, either as a preincubation or in co-incubation. Instead, TGF $\alpha$-PE38 enhanced the specific lysis of a human breast cancer cell line by CTLs. These results support the enhancement of tumor cell killing using two targets for immunotherapy, as we have previously shown with two different targets for developing CTLs (20).

In summary, the targeting of two tumor antigens by two different immunotherapeutic modalities was shown to be feasible, non-toxic and superior to either of the individual modalities in the specific lysis of a human breast cancer cell line. The combination of these two modalities of therapy, targeting two different tumor antigens, may be of use in humans in preventing recurrence of breast cancer following autologous hematopoietic stem cell transplantation $(21,22)$, by purging the contaminating breast cancer cells, which are associated with recurrence (23), from the hematopoietic stem cells. In addition, these two modalities of immunotherapy may be of benefit in vivo for humans with breast cancer with or without other therapies, including following autologous hematopoietic stem cell transplantation.

\section{Acknowledgements}

The authors are grateful to the Coffee Memorial Blood Center (Amarillo, TX, USA) and the Harrington Cancer Center (Amarillo, TX, USA) for the PBMCs, and to those mentioned in the text for materials and/or services. Gigi O'Connell participated in the initial phase of the studies. This study was supported in part by VA medical research funds (no. 0006), the Harrington Research Foundation (Amarillo, TX, USA), the Women's Health Research Institute, Texas Tech University Health Sciences Center (Amarillo, TX, USA) and the Intramural Research Program of the NIH, National Cancer Institute, Center for Cancer Research.

\section{References}

1. Siegall CB, FitzGerald DJ and Pastan I: Selective killing of tumor cells using EGF or TGF alpha-Pseudomonas exotoxin chimeric molecules. Semin Cancer Biol 1: 345-350, 1990.

2. Siegall CB, Xu YH, Chaudhary VK, Adhya S, Fitzgerald D and Pastan I: Cytotoxic activities of a fusion protein comprised of TGF alpha and Pseudomonas exotoxin. FASEB J 3: 2647-2652, 1989.

3. Prestrelski SJ, Arakawa T, Wu CS, O'Neal KD, Westcott KR and Narhi LO: Solution structure and dynamics of epidermal growth factor and transforming growth factor alpha. J Biol Chem 267 : 319-322, 1992.

4. Chiron MF, Fryling CM and FitzGerald D: Furin-mediated cleavage of Pseudomonas exotoxin-derived chimeric toxins. J Biol Chem 272: 31707-31711, 1997.

5. Phillips PC, Levow C, Catterall M, Colvin OM, Pastan I and Brem H: Transforming growth factor- $\alpha-P$ seudomonas exotoxin fusion protein (TGF- $\alpha$-PE38) treatment of subcutaneous and intracranial human glioma and medulloblastoma xenografts in athymic mice. Cancer Res 54: 1008-1015, 1994.

6. Wright SE, Khaznadar R, Wang Z, et al: Generation of MUC1-stimulated mononuclear cells using optimized conditions. Scand J Immunol 67: 24-29, 2008.

7. Wright SE, Rewers-Felkins KA, Quinlin IS, et al: Adoptive immunotherapy of mucin1 expressing adenocarcinomas with mucin1 stimulated human peripheral blood mononuclear cells. Int J Mol Med 9: 401-404, 2002.

8. Quinlin IS, Burnside JS, Dombrowski KE, Phillips CA, Dolby N and Wright SE: Context of MUC1 epitope: immunogenicity. Oncol Rep 17: 453-456, 2007.

9. Wright SE, Kilinski L, Talib S, et al: Cytotoxic T lymphocytes from humans with adenocarcinomas stimulated by native MUC1 mucin and a mucin peptide mutated at a glycosylation site. J Immunother 23: 2-10, 2000.

10. WrightSE,Rewers-Felkins KA,Quinlin IS, etal: MHC-unrestricted lysis of MUC1-expressing cells by human peripheral blood mononuclear cells. Immunol Invest 37: 215-225, 2008.

11. Alajez NM, Schmielau J, Alter MD, Cascio M and Finn OJ: Therapeutic potential of a tumor-specific, MHC-unrestricted T-cell receptor expressed on effector cells of the innate and the adaptive immune system through bone marrow transduction and immune reconstitution. Blood 105: 4583-4589, 2005.

12. Kanof ME and Smith PD: Preparation of human mononuclear cell populations and subpopulations. In: Current Protocols in Immunology. Coligan JE (ed). John Wiley \& Sons, Inc., New York, NY, pp7, 2009. 
13. Barnd DL, Lan MS, Metzgar RS and Finn OJ: Specific, major histocompatibility complex-unrestricted recognition of tumor-associated mucins by human cytotoxic T cells. Proc Natl Acad Sci USA 86: 7159-7163, 1989.

14. Roehm NW, Rodgers GH, Hatfield SM and Glasebrook AL: An improved colorimetric assay for cell proliferation and viability utilizing the tetrazolium salt XTT. J Immunol Methods 142: 257-265, 1991

15. Jost LM, Kirkwood JM and Whiteside TL: Improved short- and long-term XTT-based colorimetric cellular cytotoxicity assay for melanoma and other tumor cells. J Immunol Methods 147: $153-165,1992$.

16. Altman SA, Randers L and Rao G: Comparison of Trypan blue dye exclusion and fluorometric assays for mammalian cel viability determinations. Biotechnol Prog 9: 671-674, 1993.

17. Bode AM, Ma W-Y, Surh Y-J and Dong Z: Inhibition of epidermal growth factor-induced cell transformation and activator protein 1 activation by [6]-gingerol. Cancer Res 61: 850-853, 2001.

18. Vennstrom L, Bysell C, Bjorkelund $\mathrm{H}$, Lundqvist $\mathrm{H}$ and Andersson K: Real-time viability assay based on $51 \mathrm{Cr}$ retention in adherent cells. Biotechniques 44: 237-240, 2008.
19. Wu MH, Liebowitz DN, Smith SL, Williams SF and Dolan ME: Efficient expression of foreign genes in human CD34+ hematopoietic precursor cells using electroporation. Gene Therapy 8: 384, 2001.

20. Petty AP, Wright SE, Rewers-Felkins KA, Yenderrozos MA, Vorderstrasse BA and Lindsey JS: Targeting migration inducting gene-7 inhibits carcinoma cell invasion, early primary tumor growth, and stimulates monocyte oncolytic activity. Mol Cancer Ther 8: 2412-2423, 2009.

21. Ross AA, Cooper BW, Lazarus HM, et al: Detection and viability of tumor cells in peripheral blood stem cell collections from breast cancer patients using immunocytochemical and clonogenic assay techniques. Blood 82: 2605-2610, 1993.

22. Rill DR, Santana VM, Roberts WM, et al: Direct demonstration that autologous bone marrow transplantation for solid tumors can return a multiplicity of tumorigenic cells. Blood 84: 380-383, 1994.

23. Braun S, Vogl FD, Naume B, et al: A pooled analysis of bone marrow micrometastasis in breast cancer. N Engl J Med 353: 793-802, 2005 